\title{
Tele-health interventions to support self-management in adults with rheumatoid arthritis: a systematic review
}

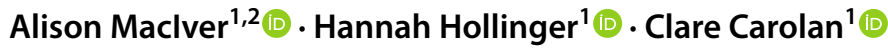

Received: 27 March 2021 / Accepted: 29 May 2021 / Published online: 16 June 2021

(c) Crown 2021

\begin{abstract}
Rheumatoid arthritis (RA), a long-term auto-immune condition is a challenging condition for patients to manage. Goals of treatment include reducing pain, decreasing inflammation, and improving an individual's overall function. Increasingly technology is being utilised to support patients to self-manage their condition. The aim of this systematic narrative review was to synthesise and critically appraise published evidence concerning the effectiveness of tele-health interventions to support self-management in RA. Bibliographic databases searched from 2014 to March 2020 included MedLINE, Embase, Cochrane Library. Search strategy combined the following concepts: (1) rheumatoid arthritis, (2) tele-health interventions, and (3) self-management. Only randomised controlled trials (RCTs) involving adults with RA were included. Titles, abstracts, fulltext articles were screened, any discrepancies were checked by a second reviewer. Risk of bias was assessed using Cochrane risk of bias tool and data were extracted utilising the Cochrane data collection form for RCT interventions along with the TiDier checklist. Due to high heterogeneity, results were not meta-analysed and instead data were synthesised narratively. The search identified 98 articles, seven were included. The completed RCTs varied in the nature of the interventions, duration/severity of RA, outcomes measured and effectiveness of the interventions. The completed RCTs included a total of 791 participants Disease duration was largely between 4 and 10 years and disease severity on average was moderate. There was extensive variation in intervention components, theories underpinning theories and outcomes measured. Five RCTs reported a positive effect on factors such as disease activity, medication adherence, physical activity and self-efficacy levels. This study suggests that tele-health interventions that are well-designed, tailored and multi-faceted can help to achieve positive self-management outcomes in RA. None of the studies showed evidence of harm.
\end{abstract}

Keywords Rheumatoid arthritis $\cdot$ Self-management $\cdot$ Tele-health interventions

\section{Introduction}

Rheumatoid arthritis (RA) is the most commonly diagnosed systemic inflammatory arthritis [1]. RA is a painful longterm condition which results in wide spread systemic inflammation, and joint damage [2]. Women, smokers, and those

\footnotetext{
Hannah Hollinger

Hannah.hollinger@uhi.ac.uk

$\triangle$ Clare Carolan

clare.carolan@uhi.ac.uk

Alison MacIver

alison.maciver2@nhs.scot

1 Department of Nursing and Midwifery, University of the Highlands and Islands, Inverness, UK

2 NHS Western Isles, Stornoway, Scotland, UK
}

who have a family history of the disease are at highest risk of developing the condition [3]. RA affects $0.5-1.0 \%$ of adults, with 5-50 per 100,000 new cases annually in industrialised countries [4]. Uncontrolled active RA can result in erosive joint damage, increasing disability, poor quality of life, and other co-morbidities [5]. Patients with RA face a high disease burden including symptoms such as pain, stiffness, fatigue and decreased muscle strength which makes activities of daily living challenging. Furthermore, RA has been linked to psychological issues such as depression, helplessness and anxiety which further impacts on everyday life [6].

Treatment advances in RA have led to substantial improvements in patients' physical and psychological outcomes, however, issues regarding fatigue, pain, reduced physical activity and quality of life still exist [7]. Poor outcomes are associated with non-adherence to medication, lack of knowledge about the condition and lack of support in 
coping and effective self-management [8]. Self-management is defined as the ability to manage symptoms, treatment and lifestyle changes which are associated with living with a chronic condition [3]. Evidence shows promoting selfmanagement can contribute to better treatment and health outcomes through addressing these issues [9]. Engaging in self-management supports patients to take responsibility for improving their health by engaging in positive health behaviours such as physical activity, fatigue management and medication adherence [10].

There is potential for tele-health interventions (i.e. interventions delivered via digital technologies such as mobile phones, computers, text messaging) to provide cost effective, safe health care. The World Health Organisation (WHO) promotes the use of tele-health to provide clinical services [8]. The European League Against Rheumatism (EULAR) also recognise the benefits of tele-health for RA patients to enhance patient engagement and self-management approaches in rheumatic diseases [7]. Tele-health interventions can support self-management in RA by using technology to provide patients the knowledge, skills and support to manage their condition [7]. Research shows that patients in remission who are familiar with modern technology would welcome the possibility of managing their own condition by using online devices or mobile phones [11].

Although the use of tele-health interventions for RA is increasingly advocated, systematic reviews to date have only focussed on the quality and features of tele-health interventions available and their potential to be used within RA [11, 12]. These studies identified that tele-health interventions increase the emphasis engaging people with RA as active partners in their care and that a demand exists for technology that is accessible, simple to use and can help with the clinical management of the condition. Najm et al. [13] systematic review assessed the content and development of self-management tele-health interventions and endorsed that patients with RA are keen to engage with technology that supports self-management. A further systematic review by McDougall et al. [14] found tele-health interventions to be effective for the diagnosis and management of inflammatory rheumatic diseases but proposed that further studies were required to determine the best uses of tele-health for the management of these conditions. Knudsen et al. [15] qualitative study on tele-health in RA revealed the need for further insight into how tele-health interventions could be developed to increase patients to have an active role in disease control. To date no systematic review has assessed how effective telehealth interventions are at supporting self-management in patients with RA.

The purpose of this review is to answer the question: 'Are tele-health interventions effective for supporting patients living with RA to self-manage their condition'? The review aims to evaluate a range of tele-health interventions and summarise the existing evidence base for their effectiveness. The aims include undertaking a systematic search and review of the literature in order to determine: (1) the extent to which tele-health interventions are effective in supporting patients to self-manage RA and (2) address implications for research and practice since no known systematic reviews of the effectiveness of tele-health interventions for supporting self-management in RA has previously been done. Examination of the literature for the usefulness and effectiveness of tele-health interventions in RA will provide insight into role that this technology could have to support self-management and improve patient outcomes.

\section{Methods}

\section{Search strategy}

The Preferred Reporting Items for Systematic Reviews \& Meta-Analysis (PRISMA) statement and guidelines guided the conduct of this systematic review [16]. The following electronic bibliographic medical databases were systematically searched to identify trials of tele-health interventions supporting self-management in adults with RA: The Cochrane Central Register of Controlled Trials (CENTRAL), Ovid MedLINE, Ovid Embase. The search terms were grouped into four concepts: (1) Rheumatoid Arthritis, (2) self-management, (3) tele-health interventions, and (4) study type. The search was limited to manuscripts published in the English language between 2014 and the present date to reflect developments in the tele-health industry and promote inclusion of contemporaneous studies. As an example, specific search terms undertaken in Ovid MedLINE on 3rd March 2020 is included (See supplementary File 1 for search strategy).

\section{Inclusion/exclusion criteria}

Randomised Controlled Trials (RCTs) were chosen as they measure the effectiveness of an intervention which addresses the research question posed in this review. Articles were included if participants were over the age of 18 and had RA, published in English, the intervention involved tele-heath technology to support self-management and incorporated outcomes of interest. (Table 1). An initial literature search conducted in March 2020 Identified 176 citations which were imported into Refworks and de-duplicated. After removing duplicates 98 articles were identified. First level screening was undertaken independently 98 titles/abstracts were screened and each article was assessed against the pre-set eligibility 
Table 1 Inclusion/exclusion criteria

\begin{tabular}{|c|c|c|}
\hline & Inclusion & Exclusion \\
\hline Language & All papers in the English language & $\begin{array}{l}\text { Non-English were excluded due to lack of translation facili- } \\
\text { ties }\end{array}$ \\
\hline Type of study & $\begin{array}{l}\text { Randomised controlled trials (RCTs), controlled non-ran- } \\
\text { domised studies and controlled before and after studies }\end{array}$ & $\begin{array}{l}\text { Qualitative research papers } \\
\text { Mixed Method papers incorporating a qualitative/quantita- } \\
\text { tive approach } \\
\text { Feasibility, pilot, quasi-experimental studies and conference } \\
\text { abstracts }\end{array}$ \\
\hline Type of intervention & $\begin{array}{l}\text { Tele-health interventions, including any digital intervention } \\
\text { accessed through a computer, mobile phone or hand-held } \\
\text { device, including web-based or desktop computer pro- } \\
\text { grammes or applications that support self-management } \\
\text { Comparison groups to the tele-health intervention would } \\
\text { be usual care or no intervention }\end{array}$ & $\begin{array}{l}\text { Tele-health interventions that do not support self-manage- } \\
\text { ment }\end{array}$ \\
\hline Type of participants & $\begin{array}{l}\text { Adults over the age of } 18 \text { of any gender with a diagnosis } \\
\text { of RA }\end{array}$ & $\begin{array}{l}\text { Populations incorporating inflammatory arthritis, osteo- } \\
\text { arthritis, juvenile idiopathic arthritis, psoriatic arthritis }\end{array}$ \\
\hline Type of outcomes & $\begin{array}{l}\text { Outcomes of interest include self-management-related } \\
\text { areas such as disease activity, including objective and } \\
\text { self-reported clinical, physiological markers of disease } \\
\text { control. Validated measures of symptoms such as fatigue, } \\
\text { pain, disability and quality of life. Further outcomes such } \\
\text { as self-efficacy and medication adherence, health care } \\
\text { utilisation will also be considered }\end{array}$ & $\begin{array}{l}\text { Subjective measures or generalised outcomes such as patient } \\
\text { satisfaction or quality of life }\end{array}$ \\
\hline Date & $\begin{array}{l}\text { Studies included will be from } 2014 \text { onwards to the present } \\
\text { date to ensure data are contemporaneous and relevant }\end{array}$ & $\begin{array}{l}\text { Papers prior to } 2014 \text { were excluded as tele-health interven- } \\
\text { tions were not so readily available to patients }\end{array}$ \\
\hline
\end{tabular}

criteria which was ordered from 1 to 6 . Inclusion criteria included language, type of study, participants, type of intervention outcomes and date. Seven studies were selected which met the inclusion criteria. Any discrepancies throughout the process were discussed with other authors $(\mathrm{HH}, \mathrm{CC})$ where there was any uncertainty, and the reasons for excluding the studies were recorded. The PRISMA flowchart Fig. 1 demonstrates this process in fuller detail.

\section{Quality assessment}

The quality appraisal tool chosen for assessing the quality of studies when undertaking a systematic review adhered to the PRISMA guidelines [16]. The Cochrane Risk of Bias tool was utilised to screen each study for bias [17]. This validated tool is recommended by Cochrane and was chosen for this review as it enables separate assessments of six specific domains of risk, including selection, performance, detection, attrition, and reporting bias. The tool was chosen as it enables a judgement to be made on whether a study has a high, low or unclear risk of bias. Risk of bias was undertaken independently with disagreements resolved by consensus with co-authors (HH, CC) (Table 2).

\section{Data extraction and analysis}

Data extraction were guided by the PRISMA statement [16] to ensure a systematic approach was adopted. Data were extracted using the Cochrane data collection form for intervention reviews: RCTs [2019]. The full-length papers were read, and data extracted, conflicts in data extraction were resolved by consensus with co-authors. Data collected included author, publication year, country of origin, details about the study population (diagnosis, mean age, disease activity, disease duration, and education level), the intervention, comparator, outcomes and study findings. Outcomes of interest related to self-management were grouped into disease control outcomes (clinical and physiological markers of disease control, health care utilisation and validated measures of symptoms) and selfmanagement process outcomes (e.g. self-efficacy, medication adherence). To help determine the effectiveness of tele-health interventions in supporting patients with RA to self-manage their condition; the Template for Intervention Description and Replication (TiDier) checklist [17] was used as an additional data extraction tool. This checklist enabled extraction of further details of the key components of interventions, including identifying the type of technology used to support self-management, characteristics, including intensity, and duration, and underlying 


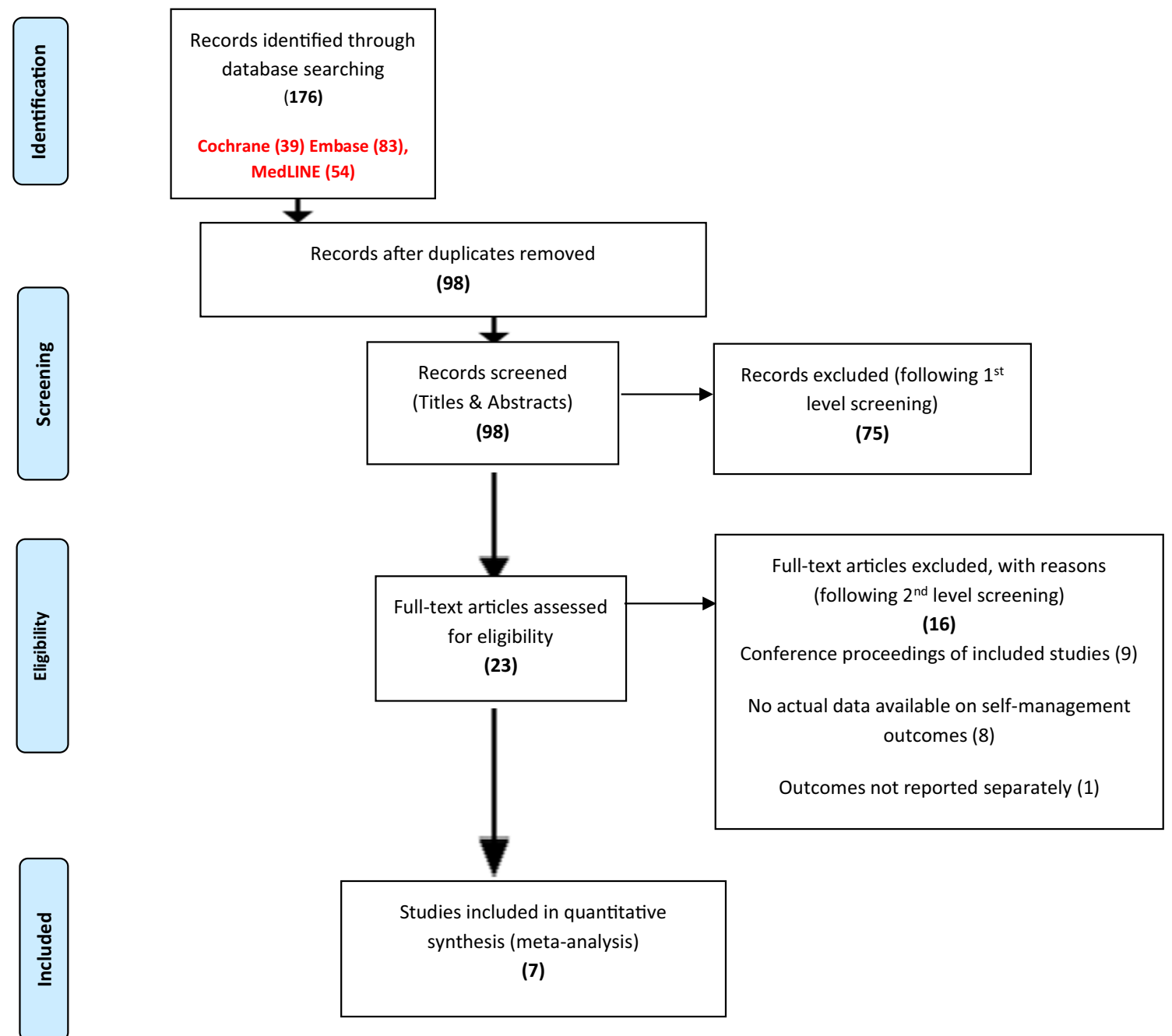

Fig. 1 Prisma flow diagram (Moher et al. 2009)

Table 2 Cochrane risk of bias tool [17]

\begin{tabular}{|c|c|c|c|c|c|c|c|}
\hline & \multicolumn{2}{|c|}{ Selection bias } & \multirow{2}{*}{$\begin{array}{l}\text { Performance bias } \\
\text { Blinding patients/ } \\
\text { personnel }\end{array}$} & \multirow{2}{*}{$\begin{array}{l}\text { Detection bias } \\
\text { Blinding } \\
\text { outcome } \\
\text { assessment }\end{array}$} & \multirow{2}{*}{$\begin{array}{l}\text { Attrition bias } \\
\text { Incomplete data }\end{array}$} & \multicolumn{2}{|l|}{ Reporting bias } \\
\hline & $\begin{array}{l}\text { Random } \\
\text { sequence } \\
\text { generation }\end{array}$ & $\begin{array}{l}\text { Allocation } \\
\text { conceal- } \\
\text { ment }\end{array}$ & & & & Selective reporting & Other biases \\
\hline Allam et al. [18] & High risk & Low risk & High risk & Unclear & Low risk & Unclear & Unclear \\
\hline Zuidema et al. [19] & Unclear & Unclear & High risk & Unclear & Low risk & Low risk & Unclear \\
\hline Kuusalo et al. [24] & High risk & Unclear & High risk & Unclear & High risk & Unclear & Unclear \\
\hline Song et al. [21] & Unclear & Unclear & High risk & Unclear & Low risk & Unclear & High risk \\
\hline Liu et al. [22] & Low risk & Low risk & High risk & Unclear & Low risk & Low risk & High risk \\
\hline Zhao \& Chen [23] & Low risk & Low risk & High risk & Unclear & Low risk & Unclear & High risk \\
\hline Salaffi et al. [20] & High risk & Low risk & High risk & Unclear & Low risk & Unclear & High risk \\
\hline
\end{tabular}


theoretical approaches the intervention. This information was then collated into tables to illustrate findings.

\section{Data synthesis}

Due to the extreme heterogeneity of the included studies in terms of participants, location, interventions and outcome measures a meta-analysis was statistically inappropriate and could not be performed. Therefore, a narrative synthesis was undertaken as interventions and associated outcomes were diverse.

\section{Results}

\section{Outcome of the search}

Figure 1 illustrates the flow of studies through the review process and outlines reasons for exclusion. Searches identified 176 potentially relevant articles which was reduced to 98 articles after removing duplicates by critiquing articles against inclusion criteria 1-4 (Table 2). Following review of title and abstracts 23 full text articles were retrieved. Of the 23 full text articles identified seven fully met the inclusion criteria 1-6 and were included in this systematic review.

\section{Study characteristics and design}

Table 3 shows details of each studies setting, participant demographics, interventions, comparator and key findings. The seven studies included in this systematic review dates of publication ranged from 2015 to 2020, six of the studies were undertaken from 2019 onwards reflecting the increasing use of tele-health interventions within healthcare. Each study involved a tele-health intervention and the comparison was usual clinical care. Three studies compared a web based tele-health intervention with usual care [18-20]. Allam et al. [18] trialled a self-management information website with specific groups accessing social support and/or gamification features. Salaffi et al. [20] \& Zuidema et al. [19] incorporated self-monitoring tools to track symptoms within their self-management website. Three studies looked at telephone based self-management education sessions as an intervention following hospital discharge compared to usual care [21-23]. One study used a mobile phone text messaging (SMS) application to improve self-management by supporting medication adherence and self-monitoring of symptoms [24]. A wide range of outcomes to measure the effectiveness of interventions were included in the RCTs. The outcome measures were categorised as follows: disease activity and related symptoms, physical activity, knowledge and markers of self-care, medication adherence and health care resource use.

\section{Quality assessment and risk of bias}

Results for the Cochrane Risk of Bias tool [17] for the included RCTs are reported in Table 2. Despite using random sequence generation participants were being selected from a group already identified to have access to either Internet or a mobile phone in several studies indicating a high risk of selection bias [18, 20,24]. The risk of detection bias was unclear across all studies as it was not certain whether blinded outcome assessment had been performed. One study was assessed to have high risk of attrition bias as the data was incomplete [24]. All studies were unclear or at high risk of bias in most domains, common issues included small numbers of participants and a lack of blinding [20-23]. Other high risk of bias included participation bias as only those who had a telephone or mobile phone were recruited [20-23]. The studies were of low-to-moderate quality affecting overall validity, reliability and generalisability.

\section{Synthesis of results}

\section{Intervention characteristics}

Theories underpinning each intervention were identified and summarised in the TIDieR intervention Table 4. This mainly outlined cognitive-behavioural approaches, including self-efficacy theory $[18,23]$, empowerment theory, social support theory [18], theory of planned behaviour [19], dual process theory [19, 21, 23], and health belief theory [21]. A treat to target approach was mentioned as a key component of supporting self-management in two studies [20,24]. Each intervention was delivered as planned with the overall aim of supporting self-management in individuals with RA.

Two web-based interventions $[18,19]$ and three telephone interventions were based on blended educational and behavioural theory [21-23]. Allam et al. [18] \& Zuidema et al. [19] supported self-management through providing education and information on RA helping individuals to self-manage symptoms by targeting beliefs to affect behaviours. Allam et al. [18] incorporated a gamification feature, this approach based on self-determination theory aims to improve patient's motivation and interaction with the website. A chat room option was available for some participants based on the theory that digital support networks may influence self-management capabilities. Behavioural theory appeared to underpin the telephone-based interventions, two were based on self-efficacy theory $[22,23]$ and one was based on the health belief model [21]. The main aim of these interventions was to empower patients to engage in positive 


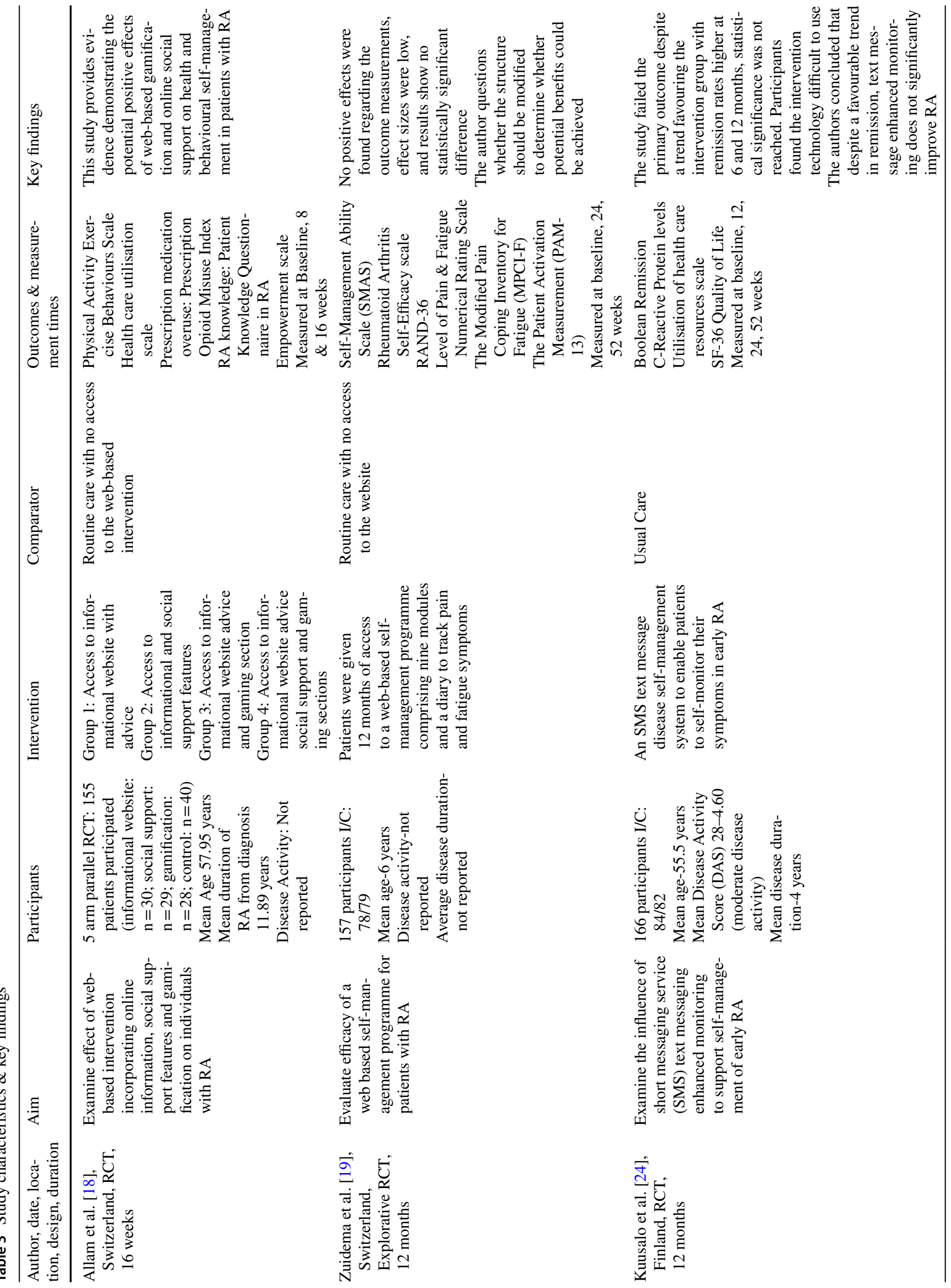




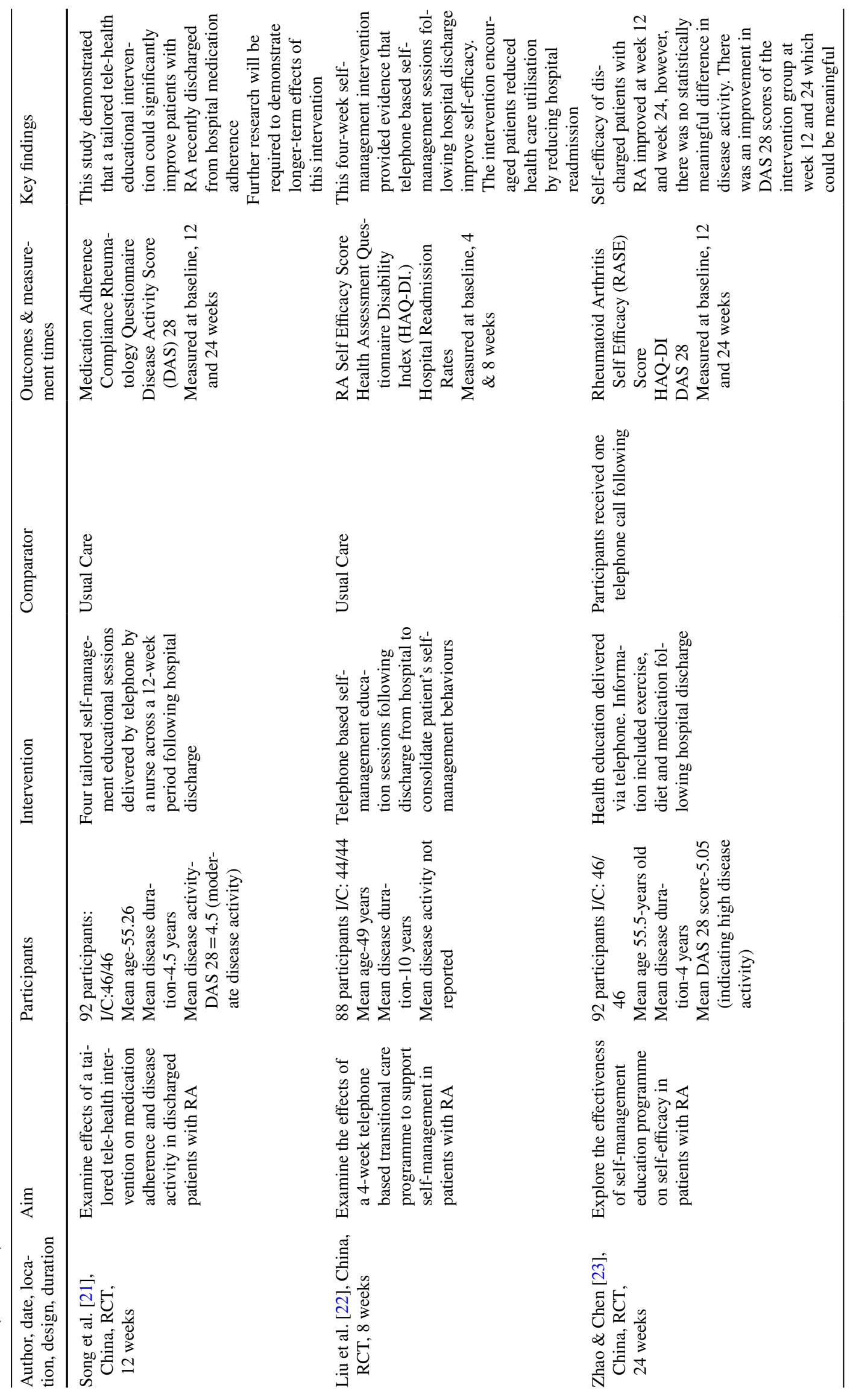




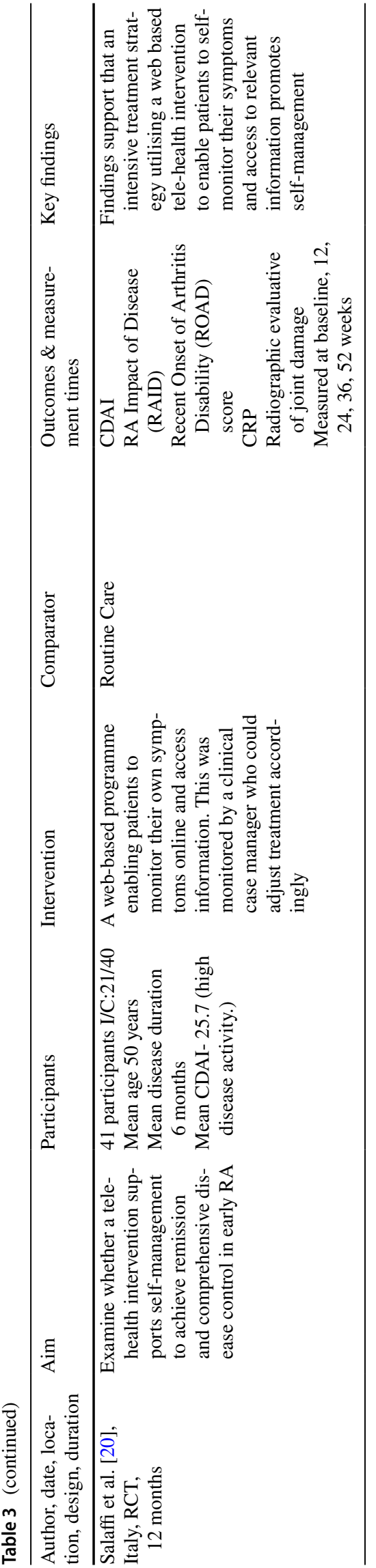

self-management behaviours through planned telephone education sessions.

Two studies [20,24] had a treat to target approach which aims to improve outcomes for patients with RA. According to NICE this is the preferred approach to provide clear direction on early treatment and tight disease control [25]. These interventions encouraged and empowered patients to be active partners in self managing their condition through online applications [24] and mobile phones [20]. These involved patients managing their condition through taking responsibility for self-monitoring of their symptoms.

\section{Effect of tele-health interventions on outcomes}

\section{Disease Activity and related symptom measures}

Zuidema et al. [19] web based self-management programme found no remarkable significant effects at six months on disease activity, pain or fatigue. The outcome measurement of the RAND-36 general health perception after twelve months showed a statistically significant effect $(9.65 .95 \%$ CI $0.83-18.48, p+0.03$ ) for those who used the intervention more with a small effect size 0.02 . Kuusalo et al. [24] selfmonitoring SMS application found no statistically significant difference in disease activity DAS 28 at 6 months despite the level of remission being higher in the intervention group. Similar DAS 28 levels were achieved in both intervention and control groups during the first 6 months, the respective mean \pm SD DAS 28 scores for the intervention and control groups were $1.92 \pm 1.12$ and $2.22 \pm 1.11$ at six months $(p=0.09)$; and $1.79+0.91$ and $2.08+1.22$ at 12 months $(p=0.28)$. Salaffi et al. [20] trialled a web based self-monitoring application and demonstrated several findings regarding disease activity which were statistically highly significant. A higher percentage in the intervention group achieved remission (38.1\% vs $25 \%$ at 12 months $p=<0.01)$. Time to achieve remission utilising the CDAI disease activity measurement $(\mathrm{CDAI}<2.8)$ was significantly shorter in the intervention group with a median of 20 weeks versus a median over 36 weeks $(p<0.001)$. The patients in the intervention group also showed a greater improvement $(p<0.001)$ in terms of functional impairment $(71.4 \%$ vs $35 \%)$ and lower radiographic progression of disease than the control group (intervention vs control group 1.47 vs $2.70 ; p=0.009$ ). Song et al. [21] telephone based self-management support measured disease activity and found there was no statistically significant difference between in disease activity at week 12 $(p=0.107)$ and week $24(p=0.096)$. Zhao \& Chen [23] telephone based self-management education found no significant difference in the DAS 28 score at week $12(p=0.099)$ and week 24 ( $p=0.096)$. In contrast Liu et al. [22] telephone based self-management education for patient post hospital discharge achieved statistically significant improvements in 


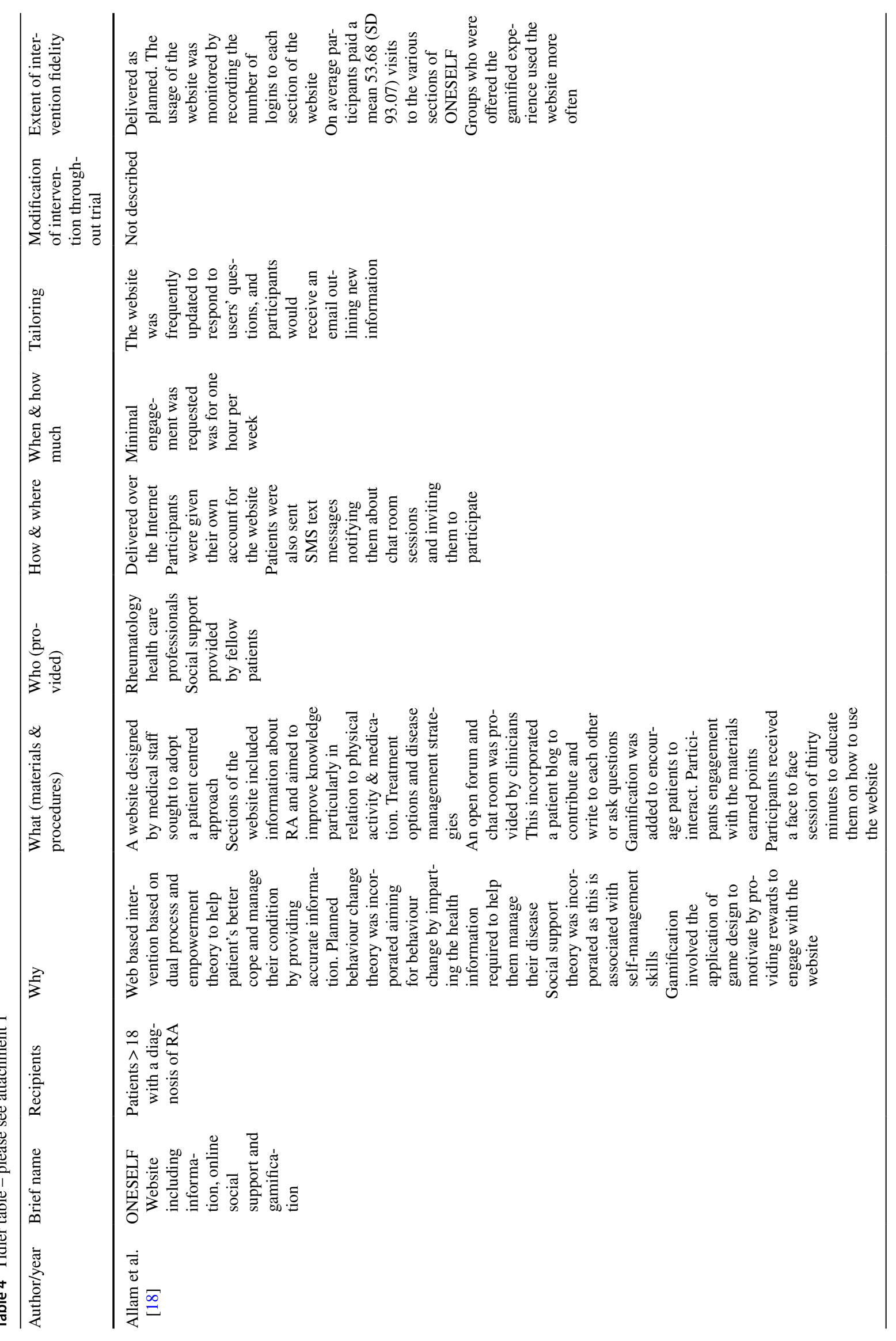




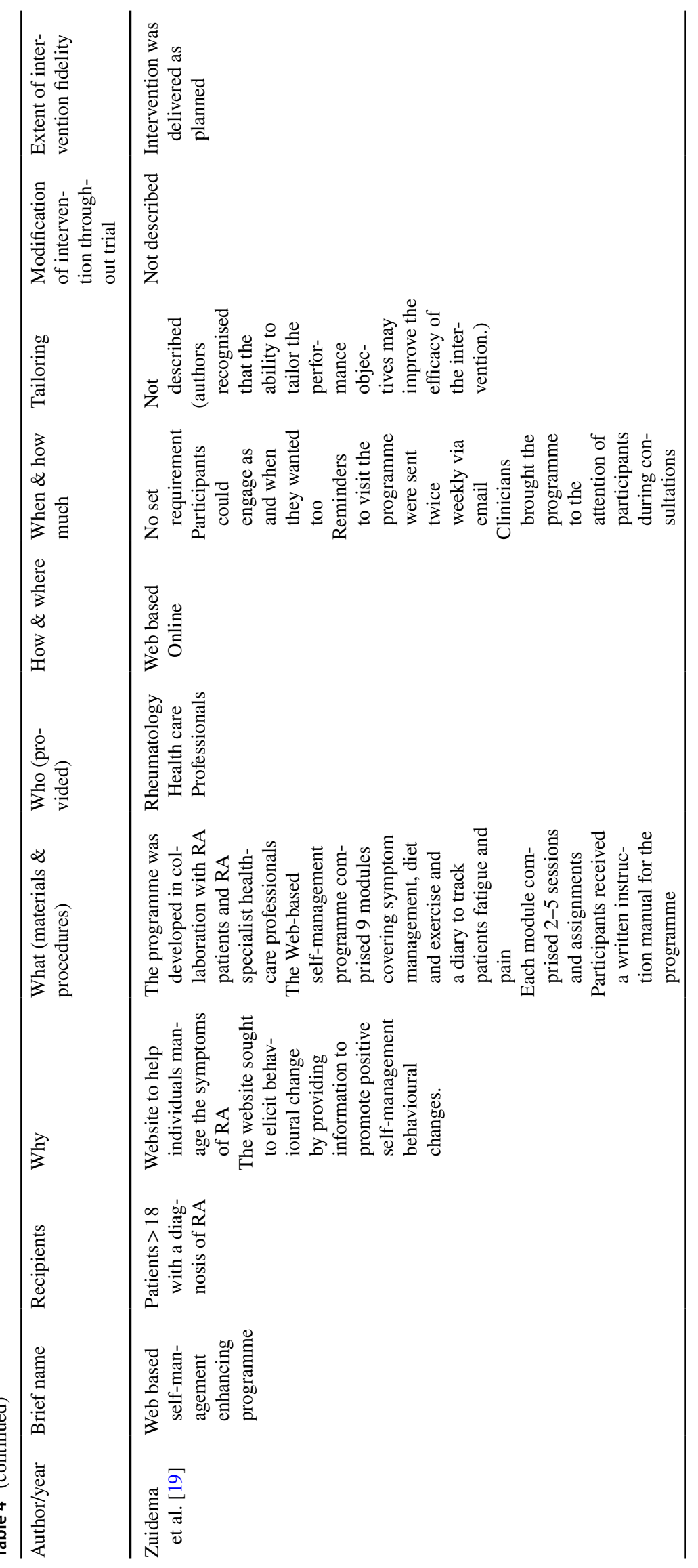




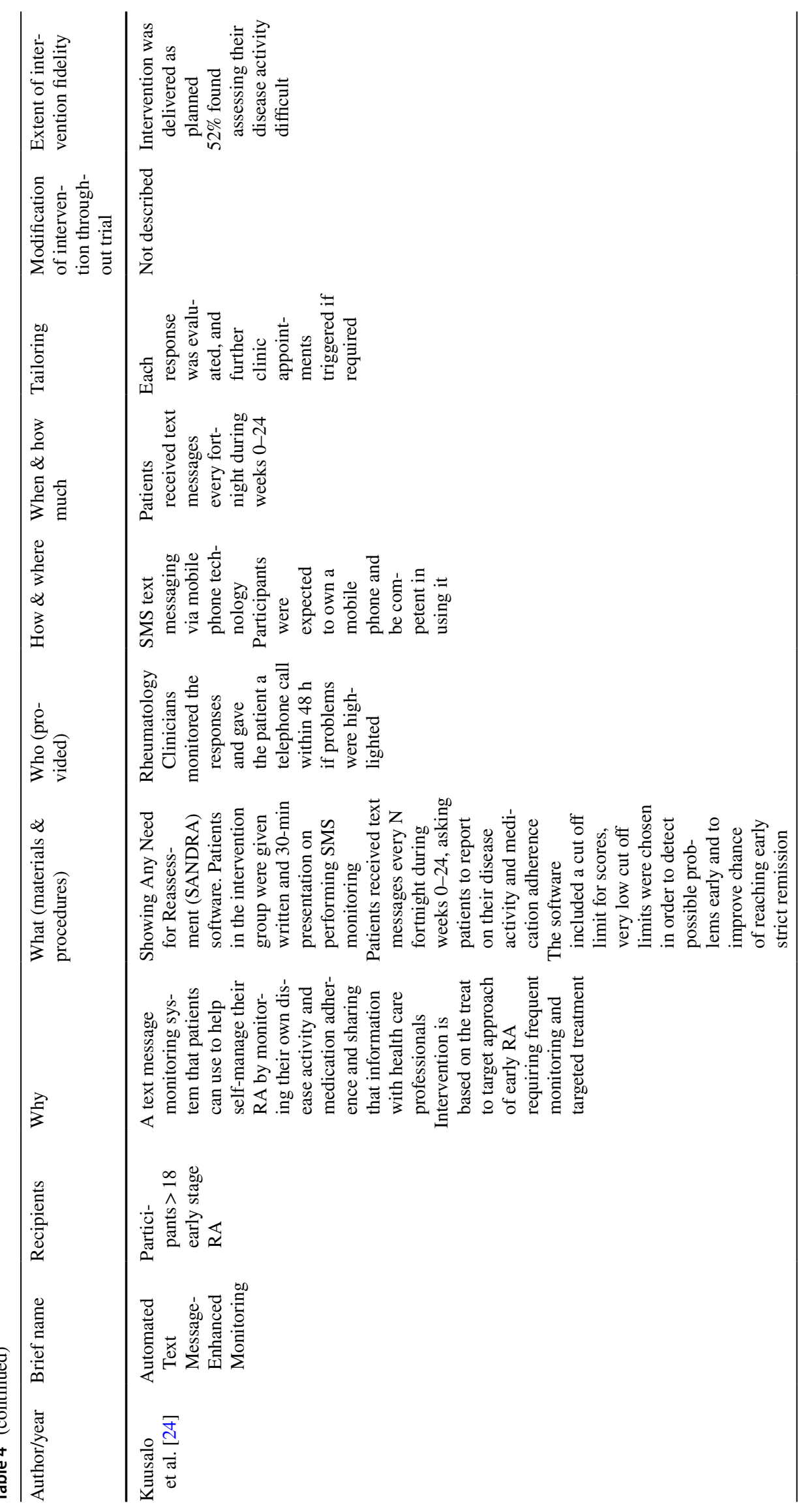




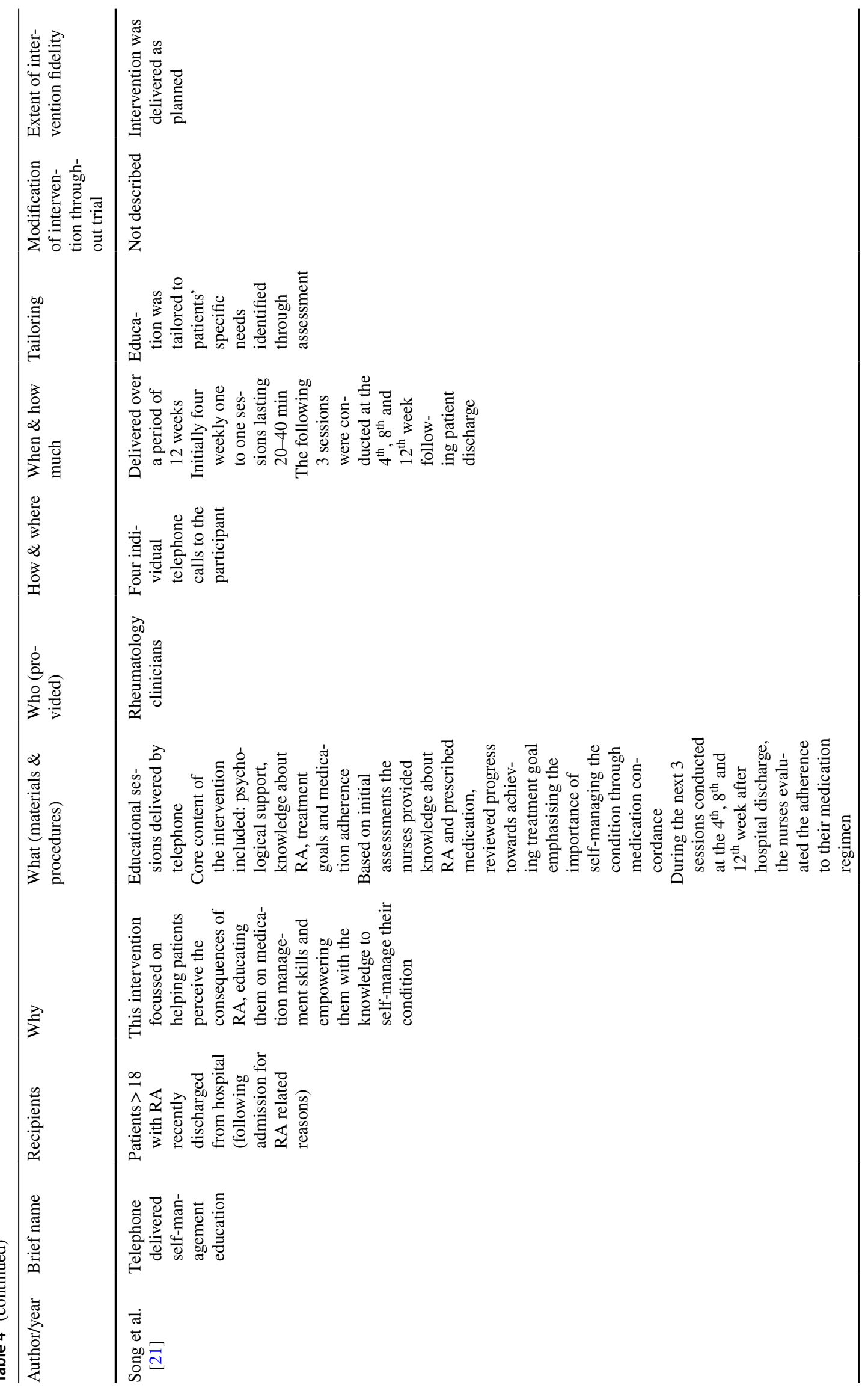




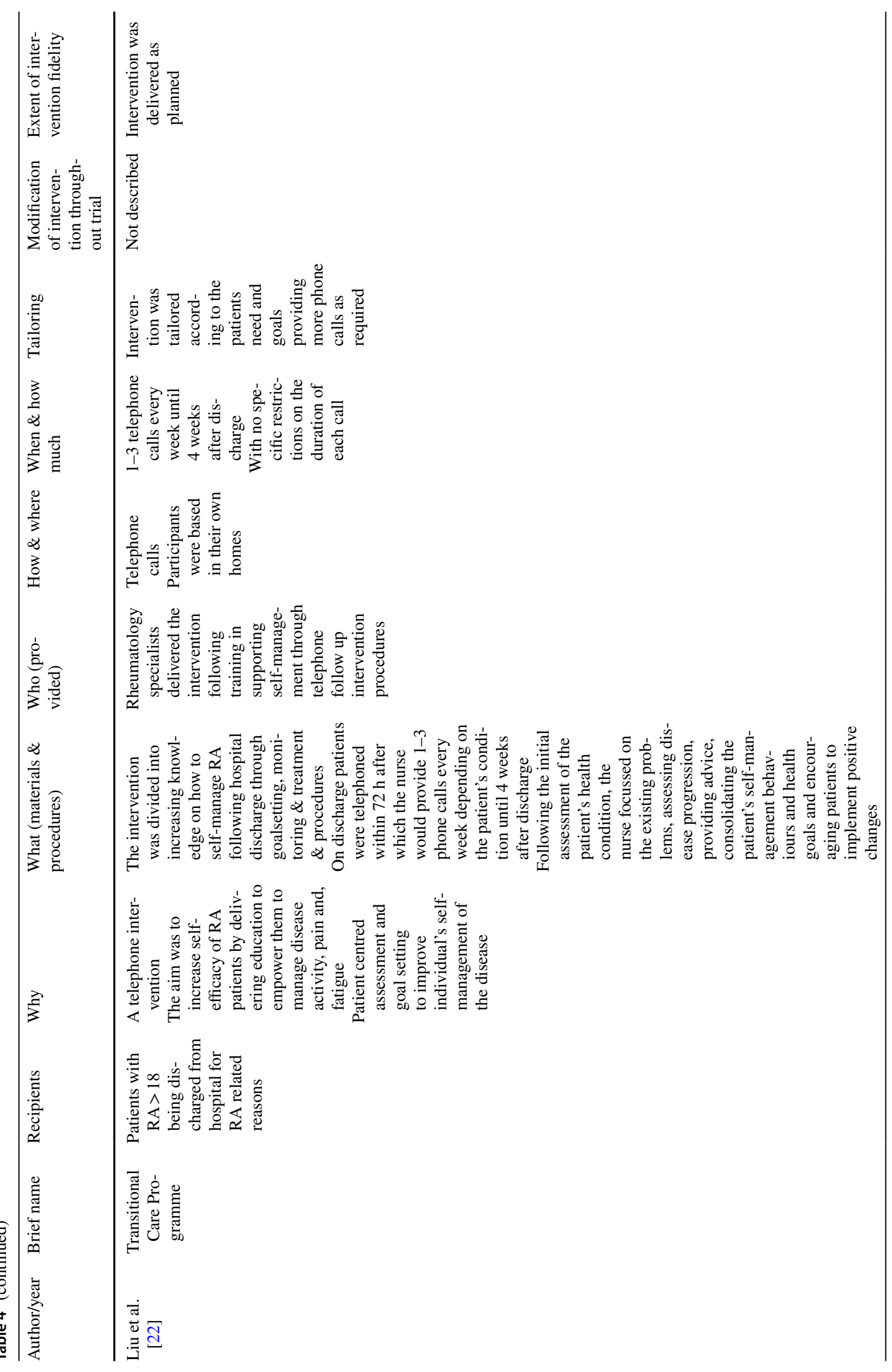




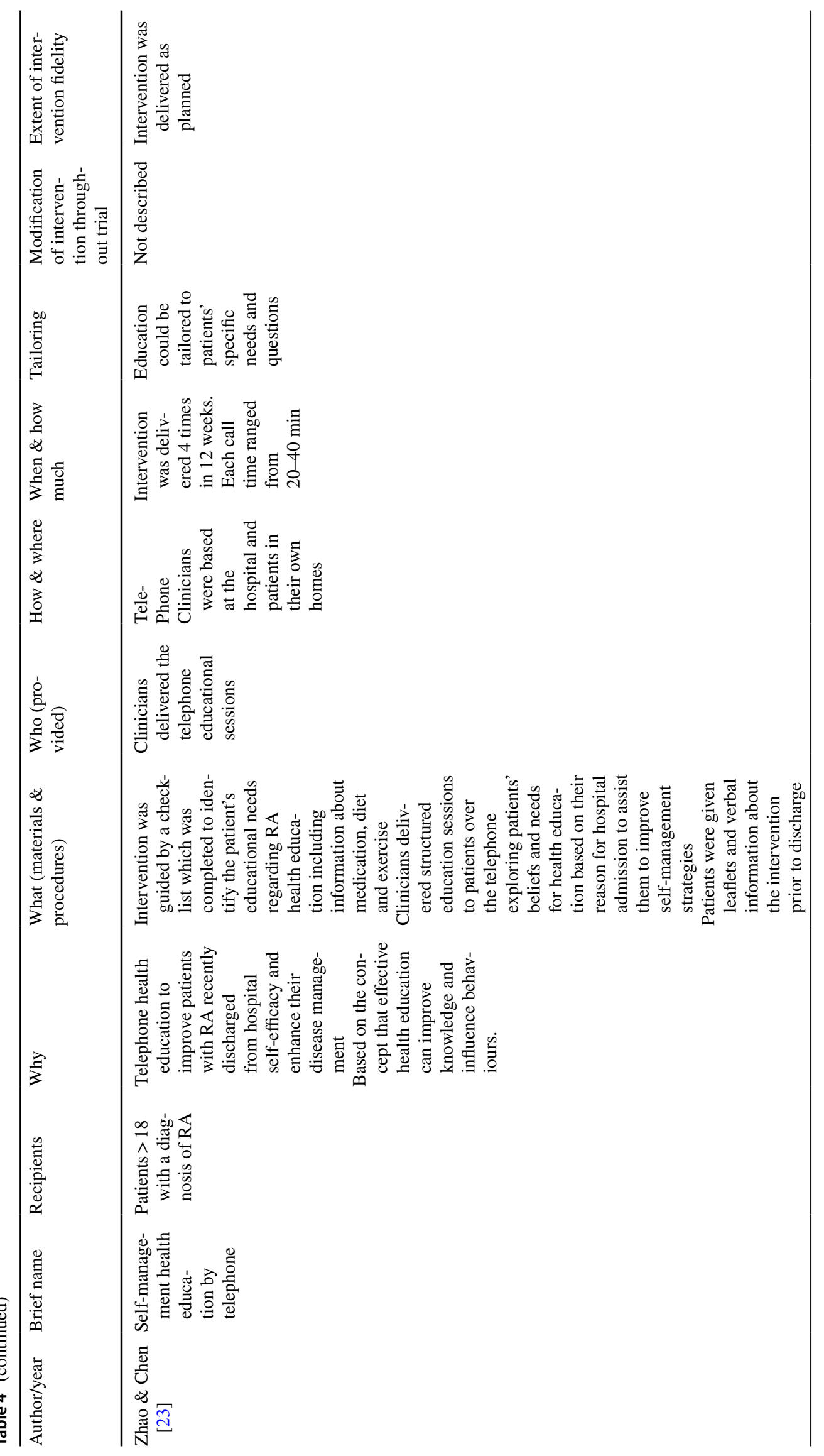




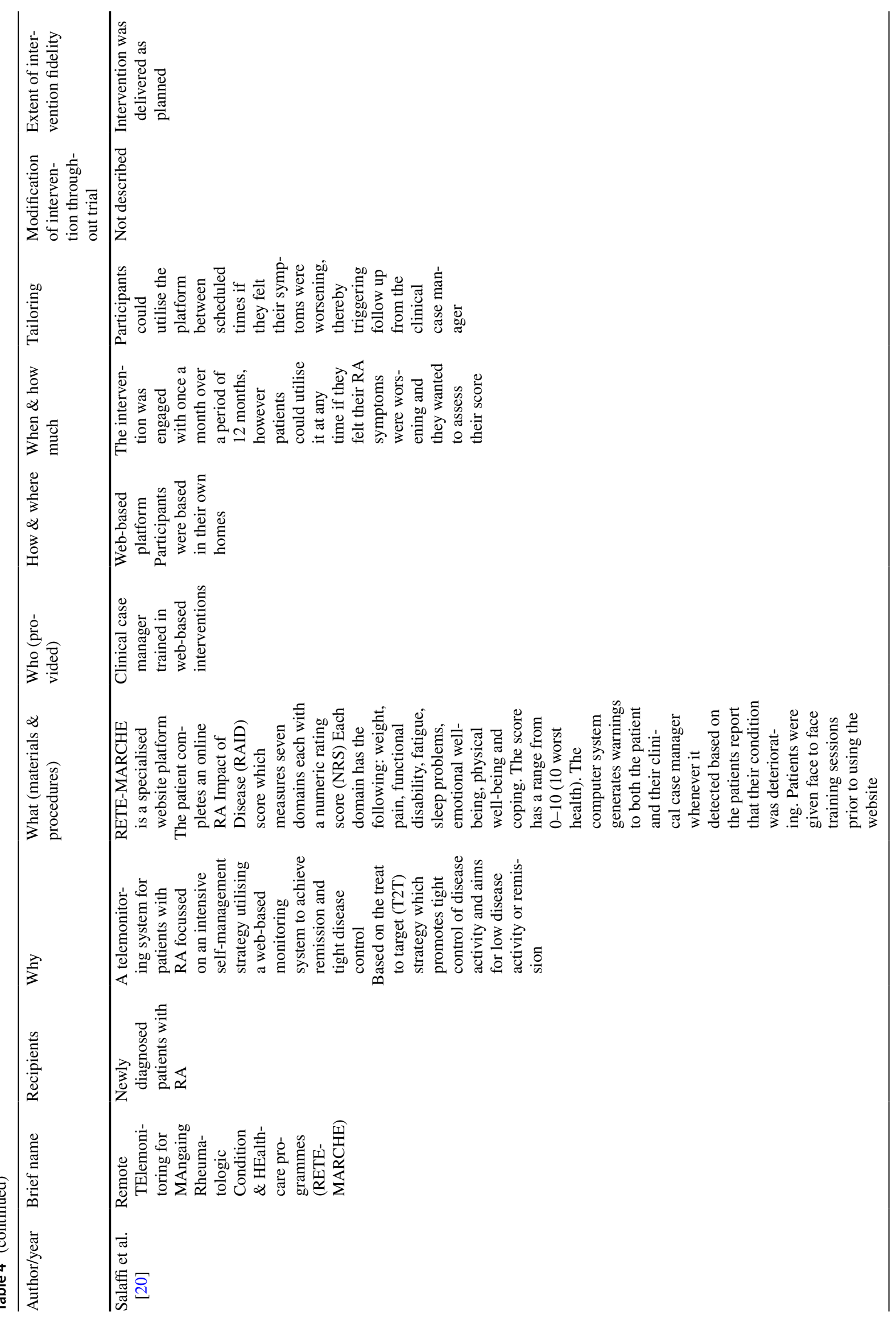


the intervention groups HAQ-DI gripping measurement at week $8(1.17$ vs $1.46 p=0.01)$. This may be attributed to the focus on encouraging engagement in hand-joint exercises resulting in better clinical outcomes.

\section{Medication adherence}

Two studies looked at medication adherence as a primary outcome. Allam et al. [18] found the online self-management website did not impact medication adherence. Utilising the Prescription Medication Overuse Scale [26] a patient reported questionnaire to measure this outcome did not show any meaningful difference across the intervention groups $(p=0.056)$. Song et al. [21] telephone self-management education measured this outcome using the self-reported Medication Adherence compliance questionnaire [27] and found after the 12th week of the intervention medication adherence was significantly higher in the intervention group compared with the control group $(p=0.014)$. Similarly, the intervention group showed a significantly higher level of medication adherence than the control group at week $24(p=0.042)$. The effect size of the intervention on medication adherence was 0.58 (95\% CI 0.12-1.03).

\section{Physical activity}

One study measured physical activity as a primary outcome [18]. Physical activity was measured using the validated patient reported Exercise Behaviours Scale [28]. The study noted an increase in physical activity at 16 weeks in the intervention group with access to additional features social support and gaming $(p=0.02)$. There were no statistically significant outcomes found for those using the website alone.

\section{Health care utilisation}

Allam et al. [18] evaluated the effect of a web based selfmanagement programme on user's health care utilisation. Utilising the validated self-reported Health Care Utilisation scale [29] to measure this primary outcome they found a significant decrease of visits to clinicians for patients accessing social support features $(p=0.01)$ and patients in accessing both social support features and gaming $(p=0.03)$. Kuusalo et al. [24] found their text-messaging to support self-monitoring application made no significant difference terms of health care utilisation. Measuring the outcome through the self-reported Utilisation of Health Care Resources scale [30] they found the number of unscheduled nurse's visits was $0.56+0.80$ in the intervention group and $0.56+0.65$ in the control group $(p=0.56)$. In the intervention and control groups, the number of unscheduled physicians' visits was
$0.13+0.44$ and $0.11+0.39(p=0.86)$ demonstrating no difference in the utilisation of healthcare resources. Liu et al. [22] measured hospital readmission scores as an outcome for the telephone self-management intervention. This did not show statistical significance although they did demonstrate clinically significant improvements as hospital readmission rates of the intervention group (4.5\%) were lower than the control group (11.4\%).

\section{Knowledge and markers of self-care}

Allam et al. [18] found that patients who had access to either social support sections or the gaming experience of their website intervention scored higher on the self-reported Empowerment scale [31] at 16 weeks $(p=0.03 \& p=0.05$, respectively). They also found that the web intervention did not improve RA knowledge levels, measured by the validated self-reported Patient Knowledge Questionnaire in RA [32]. This outcome did not show any significant difference between control and intervention groups $(p-0.06)$. Zhao \& Chen [23] found that telephone self-management education following discharge from hospital had a significant effect on self-efficacy. At baseline there was no significant difference in self-efficacy $(p=0.072)$ between the intervention group and control group. However, in the 12th and 24th week after initiating the intervention the validated patient reported Rheumatoid Arthritis Self Efficacy (RASE) [33] score was statistically highly significant $(p=<0.001)$.

\section{Discussion}

Five studies reported statistically significant outcomes to varying degrees [18, 20-23]. Zhao \& Chen [20] and Liu et al. [22] found that tailored telephone self-management education following hospital discharge improved self-efficacy. This was measured using the patient reported outcome (PRO) Rheumatoid Arthritis Self Efficacy Score (RASE) [33]. Barlow et al. [34] endorse the RASE score to be a reliable and valid measure for people with arthritis and as a useful to evaluate self-management engagement. Liu et al. [22] assessed effectiveness over eight weeks and Zhao \& Chen [23] up to 24 weeks. Further outcome measurements associated with improved self-efficacy such as medication adherence, physical activity and health care utilisation could have been considered in these studies to assess wider effects of the interventions. It would also have been of further interest to see how improvements in self-efficacy that these studies demonstrated impacted upon self-management behaviours over a longer period. Previous studies have shown self-efficacy to be a strong predictor of positive self-management behaviours among patients with other long-term conditions [35-37]. 
Song et al. [21] also found benefit from a tailored telephone delivered self-management support with significant improvement in medication adherence scores. This positive effect was self-reported through a validated questionnaire. Disease activity scores, however, were not improved although the effects of the intervention were only measured over the short-term 24 weeks. Longer-term effects of the intervention on other associated RA outcomes such as pain or fatigue scores could also have been considered. Chalfont et al. [38] supports that tele-health interventions focussed on improvement of patient self-efficacy and selfmanagement may lead to improved health behaviours. These studies were implemented to support patients to self-manage on discharge from hospital which has been recognised as a vulnerable time for patients. Transitional discharge care describes self-management as a three-tiered simultaneous approach requiring knowledge, planning and ability to help patients manage their condition [39]. These findings suggest tele-health interventions may have an important role to play in supporting patients to selfmanage following hospital discharge.

The tele-health interventions described in this review incorporated a range of self-management features. Findings demonstrate that tailoring interventions with multiple features or more intensive interventions may be associated with greater benefits [18, 20]. Vorderstrasse et al. [40] found that a tailored multiplatform website incorporating interactive components improved clinical, behavioural and psychosocial self-management outcomes in long-term conditions. Salaffi et al. [20] web-based intervention showed a highly significant improvement in disease activity supported by radiographic evidence over twelve months. Allam et al. [18] demonstrated that a web-based intervention incorporating gamification and social support features demonstrated significant improvements in physical activity and empowerment levels and a decrease in utilisation of health care resources. Johnson et al. [41] supports that gamification is an emerging strategy which can be beneficial to health and well-being. Further research with larger samples is required to derive meaningful conclusions on the effectiveness of these interventions to support self-management in RA patients.

Two included studies did not demonstrate any statistically significant differences on either the primary or secondary outcomes [19, 24]. Kuusalo et al. [24] tele-health intervention was based on the Treat to Target approach and promoted self-monitoring of RA symptoms [42]. Zuidema et al. [19] did not find any positive effects associated with a web-based tool to support self-management. This was surprising as the interventions were similar in both content and theory to other online self-management interventions which show positive effects in other chronic conditions [44-46]. Zuidema et al. [19] concluded that this could be due to the outcome measures chosen or perhaps the need to add a tailoring aspect to their intervention. Voncken et al. [47] supports that tailoring self-management interventions enhances patient engagement and the effectiveness of the intervention. Ammerlaan et al. [48] supports that tailoring an online RA self-management website by identifying individual goals and customising interventions improved usefulness and effectiveness.

In two studies was that participants had difficulty utilising intervention technology to undertake assessment of their own symptoms which affected their ability to participate $[16,21]$. Both study authors acknowledged that they may need to redesign their interventions to be more user friendly and that patients should also be involved in the design process of future interventions. Education regarding how to use the technology was also limited and participants may have benefited from further training. Tuckson et al. [43] notes the importance of designing tele-health technology to be user friendly along with education to promote ease of access.

Overall, this review found the evidence of the effectiveness of tele-health interventions to support self-management to be inconclusive but promising. This is like the findings reported by other reviews of tele-health within other longterm conditions [49-51]. A consistent conclusion reflected in the findings of this review is that utilising tele-health interventions was not associated with worse outcomes or harm to any patient. Taking this in context it appears that whilst not consistently superior to usual care, tele-health interventions provide a safe alternative mode of delivery for supporting individuals to manage their RA. Whilst there are some promising indications of benefits that may be associated with effectiveness of the interventions it may be that sample sizes were too small to detect differences, or tools used to measure outcomes were unable to detect significant differences between groups.

\section{Limitations and future research}

There were several limitations identified in this narrative review. Searches were limited to three databases due to time constraints and no access to an information specialist. Keywords could have been further refined to enable a more comprehensive literature search. A further limitation is that the search was also limited to studies published in English and did not look for non-English publications or unpublished literature, so it is possible that relevant studies were missed. The degree of bias within this review by only including studies published in English and the likely associated publication bias with including only published papers is acknowledged. However, the tools used in the review were rigorous and are of a high quality for both undertaking the search and extracting including the Cochrane risk of bias tool, Cochrane data 
extraction tool and TidIER Checklist. The methodological assessment tools used in the review are in line with the recommendations of the PRISMA statement [16].

The search identified that the studies were heterogeneous in terms of the intervention approaches, outcomes and associated contexts. The heterogeneity resulted in a further limitation as the small number of articles and associated diversity prevented the study findings being subject to a meta-analysis. The quality appraisal identified that the studies were largely deemed to be of low to moderate quality and at a high risk of bias. The sample sizes, outcome measures, short-term evaluation of interventions and locations of the studies raises further issues around the validity, reliability and generalisability of the findings from this review. Despite these limitations this review provides valuable insight into the effectiveness of tele-health interventions to support selfmanagement in RA.

Further high-quality research is required to assess the long-term effectiveness of tele-health interventions and future trials undertaken should ensure objective outcomes are measured alongside PRO or subjective measures to increase the validity and reliability of results. Kilic et al. [52] supports that PROs are helpful in providing information to accompany clinical investigations and can be used to assist with guiding patient care, such as determining whether a clinic visit, or treatment changes are necessary. This review has highlighted for the purpose of assessing the effectiveness of tele-health interventions to support self-management that it would also be helpful if objective measures such as blood tests and radiographic evaluation were studied alongside PRO measures to support validity of findings.

The design of tele-health interventions was highlighted as an important aspect of enhancing effectiveness and patient engagement. Further research will determine the most effective behavioural and educational theories on which to base interventions. Multi-platforms and tailoring of tele-health interventions were more likely to demonstrate efficacy and interactive aspects such as social support and gamification require further exploration $[18,20]$. There is growing evidence that tailoring tele-health interventions is a more successful approach and this will be an important issue to consider for future research [53]. This review also suggests that patients should be involved in the designing of tele-health interventions to promote engagement and usability. Clinicians must ensure that patients receive enough education to improve tele-health intervention literacy. Salisbury et al. [54] supports that the decision to utilise tele-health intervention to support self-management requires consensus between patient and clinicians. Further studies will help determine the wider impact of tele-health interventions on health care utilisation and associated potential benefits such as improved healthcare access and cost effectiveness.

\section{Conclusion}

This review has highlighted that the published literature regarding the effectiveness of tele-health intervention to support self-management in RA is extremely heterogeneous. The existing evidence is limited and has not yet proven the effectiveness of tele-health interventions although there are indicators regarding its usefulness to support self-management. There are signs within this review that positive self-management outcomes are linked with tele-health interventions that are well designed, tailored and multi-faceted. Going forward tele-health interventions for individuals with RA should be patient centred, building on specific selfmanagement theory and ensuring adequate resources are invested in education and training for users. Technologically the benefit of adding dynamic elements such as gamification to enhance interventions requires further consideration, however, simple approaches such as basic telephone interventions to support self-management have also shown to be of value in this review. Larger scale RCTs of tele-health interventions to support RA self-management are now required along with the exploration of objective validated outcomes and measurement of long-term effects. Determining the extent to which the benefits of tele-health can be harnessed to support selfmanagement in RA will be of utmost importance as virtual care becomes increasingly utilised and especially so in the health culture of the current pandemic.

Supplementary Information The online version contains supplementary material available at https://doi.org/10.1007/s00296-021-04907-2.

Author contributions All authors (AM. HH, CC) had a substantial contribution to study conception and design. AM performed data acquisition. All authors had a substantial contribution to analysis and interpretation of data and drafting the article or revising it critically for important intellectual content. All authors read and approved the final manuscript. No external editing/information facilitation support was involved.

Funding No funding has been received in support of the work published in this article.

\section{Declarations}

Conflict of interest A MacIver declares she has no conflict of interest. $\mathrm{H}$ Hollinger declares no conflict of interest. Dr Clare Carolan declares no conflict of interest.

Ethical standards This article does not contain any studies with human participants or animals performed by any of the authors.

Open Access This article is licensed under a Creative Commons Attribution 4.0 International License, which permits use, sharing, adaptation, distribution and reproduction in any medium or format, as long as you give appropriate credit to the original author(s) and the source, provide a link to the Creative Commons licence, and indicate if changes were made. The images or other third party material in this article are 
included in the article's Creative Commons licence, unless indicated otherwise in a credit line to the material. If material is not included in the article's Creative Commons licence and your intended use is not permitted by statutory regulation or exceeds the permitted use, you will need to obtain permission directly from the copyright holder. To view a copy of this licence, visit http://creativecommons.org/licenses/by/4.0/.

\section{References}

1. Singh J, Saag K, Bridges S, Akl E, Bannuru R, Sullivan M, Vaysbrot E, McNaughton C, Osani M, Shmerling RH (2015) American college of rheumatology guideline for the treatment of rheumatoid arthritis. Arthritis Rheumatol 68(1):1-26. https:// doi.org/10.1002/acr.22783

2. Smolen JS, Aletaha D (2015) Rheumatoid arthritis therapy reappraisal: strategies, opportunities and challenges. Nat Rev Rheumatol 11(5):276-289. https://doi.org/10.1038/nrrheum.2015.8

3. Burmester GR, Hope JE (2017) Novel treatment strategies in rheumatoid arthritis. The Lancet 389(10086):2338-2348. https://doi. org/10.1016/S0140-6736(17)31491-5

4. Riel P, Alten R, Combe B, Abdulganieva G, Gousquet P, Courtenay M, Curiale C, Gomez-Centeno A, Haugeberg G, Leeb B, Puolakka K, Ravelli A, Rintelen B, Sarzi-Puttini P (2016) Improving inflammatory arthritis management through tighter monitoring of patients and the use of innovative electronic tools. Rheumatic \& Musculoskeletal Dis 2:e000302. https://doi.org/10.1136/rmdop en-2016-000302

5. Marengo MF, Suarez-Almazor ME (2015) Improving treatment adherence in patients with rheumatoid arthritis: what are the options? Int J Clin Rheumatol 10(5):345. https://doi.org/10.2217/ ijr.15.39

6. Ankawi B, Kerns RD, Edmond SN (2019) Enhancing motivation for change in the management of chronic painful conditions: a review of recent literature. Curr Pain Headache Rep 23(75):1-8. https://doi.org/10.1007/s11916-019-0813-x

7. Dejaco C, Putrik P, Unger J (2018) EULAR 'points to consider' for the conduction of workforce requirement studies in rheumatology. Rheumatic Musculoskeletal Dis Open 4:1-8. https://doi.org/ 10.1136/rmdopen-2018-000780

8. World Health Organization (WHO) (2016) Global diffusion of eHealth: Making universal health coverage achievable: Report of the third global survey on eHealth. World Health Organization Geneva, Switzerland.

9. Thurah A, Stengaard K, Axelsen M, Fredeberg U, Schougaard L, Hjollund N, Pfeiffer-Jensen M, Laurberg T, Tarp U, Lomborg K, Maribo T (2018) Tele-health follow up strategy for tight control of disease activity in Rheumatoid Arthritis: Results of a Randomised Controlled Trial. Arthritis Care \& Research 70(3):353-360. https://doi.org/10.1002/acr.23280.

10. Dixon WG, Michaud K (2018) Using technology to support clinical care and research in rheumatoid arthritis. Curr Opin Rheumatol 30(3):276-281. https://doi.org/10.1097/BOR.0000000000 000485

11. Srikesavan C, Bryer C, Ali U, Williamson E (2019) Web based rehabilitation interventions for people with rheumatoid arthritis: a systematic review. J Telemed Telecare 25(5):263-275. https:// doi.org/10.1177/1357633X18768400

12. Grainger R, Townsely H, White B, Langlotz T, Taylor W (2017) Apps for people with rheumatoid arthritis to monitor their disease activity: a review of Apps for best practice and quantity. JMIR Mhealth Uhealth 5(2):e7. https://doi.org/10.2196/mhealth.6956

13. Najm A, Gossec L, Weill C, Benoist D, Berenbaum F, Nikiphorou E (2019) Mobile health apps for self-management of rheumatic and musculoskeletal diseases: systematic literature review. JMIR
Mhealth Uhealth 7(11):1-10. e14730. https://doi.org/10.2196/ 14730

14. McDougall J, Ferucci E, Glover J, Fraenkel L (2017) Telerheumatology: a systematic review. Arthritis Care Res 69(10):1546-1557

15. Knudsen L, Thurah A, Lomborg K (2018) Experiences with telehealth follow up in patients with rheumatoid arthritis: a Qualitative Interview Study. Arthritis Care Res 70(9):1366-1372

16. Moher D, Liberati A, Tetzlaff J, Althman DG (2009) The PRISMA Group. Preferred reporting items for systematic reviews and metaanalyses: the PRISMA statement. Br Med J 339:1-8. https://doi. org/10.1136/bmj.b2535

17. Higgins JPT, Green S (2019) Cochrane handbook for systematic reviews of interventions Version 5.1.0. The Cochrane Collaboration, 2019. Available at: https://training.cochrane.org/handbook/ current. Accessed Mar 2020

18. Allam A, Kostova Z, Nakamoto K, Schulz P (2015) The effect of social support features \& gamification on a web-based intervention for rheumatoid arthritis patients: randomized controlled trial. J Med Internet Res (JMIR) 17(1):1-19. https://doi.org/10.2196/ jmir.3510

19. Zuidema R, Dulmen S, Sanden M, Meek I, Ende C, Fransen J, Gaal B (2019) Efficacy of a web-based self-management enhancing program for patients with rheumatoid arthritis: explorative randomized controlled trial. J Med Internet Res 21(4):e12463:. https://doi.org/10.2196/12463

20. Salaffi F, Carotti M, Ciapetti A, Carlo M, Gasparini S, Farah S, Gutierrez M (2016) 'Effectiveness of a telemonitoring intensive strategy in early rheumatoid arthritis: comparison with the conventional management approach.' BMC Musculoskeletal Disorders 17(146):1-11. https://doi.org/10.1186/s12891-016-1002-2.

21. Song Y, Reifsinder E, Faan S, Xia M (2019) 'A randomized controlled trial of the effects of a telehealth educational intervention on medication adherence and disease activity in rheumatoid arthritis patients. J Adv Nurs 76(5):1172-1181. https://doi.org/10. 1111/jan.14319

22. Liu H, Gao L, Zhang W, Wang J, Cao B (2020) Effects of a 4-week transitional care programme on rheumatoid arthritis patient's selfefficacy, health status, and readmission in China: A randomized controlled trial. Int J Nursing Practice 26(4):1-12. https://doi.org/ 10.1111/ijn.12817

23. Zhao S, Chen H (2019) Effectiveness of health education by telephone follow-up on among discharged patients with rheumatoid arthritis: a randomised control trial. J Clin Nurs 28:3840-3847. https://doi.org/10.1111/jocn.15002

24. Kuusalo L, Sokka-Issler T, Kautiainen H, Ekman P, Kauppi M, Pirila L, Rannio T, Uutela T, Yli-Kerttula T, Puolakka K (2020) Automated text message-enhanced monitoring versus routine monitoring in early rheumatoid arthritis: a randomized trial. Arthritis Care Res 72(3):319-325. https://doi.org/10.1002/acr. 23846

25. National Institute for Health \& Care Excellence (NICE) (2018) Rheumatoid Arthritis in Adults: Management. NICE, London. https://www.nice.org.uk/guidance/ng100. Accessed 16th Mar 2020

26. Knisley J, Wunch M, Cropsley K, Campbell E (2008) Prescription medication misuse index: a brief questionnaire to assess misuse. J Substance Abuse Treatment 35(4):380-386. https://doi.org/10. 1016/j.jsat.2008.02.001

27. Morisky D, Green L, Levine D (1986) Concurrent \& predictive validity of a self-reported measure of medication adherence. Medical Care 24(1)(1):67-74. https://doi.org/10.1097/00005650198601000-00007.

28. Lorig K, Stewart A, Ritter P, Gonzalez V, Laurent D, Lynch J (1996) Outcome measures for health education and other health care interventions. Sage Publications, Thousand Oaks California 
29. Ritter P, Stewart A, Kaymaz H, Sobel D, Block D, Lorig K (2001) Self-reports of health care utilisation compared to provider records. J Clin Epidemiol 54(2):136-141. https://doi.org/10.1371/ journal.pone. 0206201

30. Smaldone A, Tsimicalls A, Stone P (2011) Measuring utilisation of health care resources: a resource utilization questionnaire. Theory of Nursing Practice 25(2):80-106. https://doi.org/10.1891/ 1541-6577.25.2.80.

31. Spreitzer G (1995) Psychological empowerment: dimensions, measurement \& validation. Acad Manag J 38(5):1442-1465. https://doi.org/10.5465/256865

32. Hill J, Bird H, Hopkins R, Lawton C, Wright V (1991) The development and use of the patient knowledge questionnaire in rheumatoid arthritis. Rheumatology 30(1):45-49. https://doi.org/10. 1093/rheumatology/30.1.45

33. Bardwell W, Nicassio PM, Weisman MH, Gevirtz R, Bazzo D (2002) Rheumatoid Arthritis Severity Scale: a brief, physiciancompleted scale not confounded by patient self-report of psychological functioning. Rheumatology 41(1):38-45. https://doi.org/ 10.1093/rheumatology/41.1.38

34. Barlow JH, Williams B, Wright CC (1997) The reliability and validity of the arthritis self-efficacy scale in a UK context. Psychol Health Med 2(1):3-17. https://doi.org/10.1080/135485097084005 56

35. Geng Z, Ogbolu Y, Wang J, Hinds PS, Qian H, Yuan C (2018) Gauging the effects of self-efficacy, social support, and coping style on self-management behaviors in Chinese cancer survivors. Cancer Nurs 41(5):1-10. https://doi.org/10.1097/NCC.00000 00000000571

36. Li SJ (2017) Compliance and self-efficacy of drug treatment in community hypertension patients. China General Practice 20:367369. https://doi.org/10.1371/journal.pone.0224869

37. Young L, Barnason S, Tran H (2015) Relationships between activation level, knowledge, self-efficacy, and self-management behavior in heart failure patients discharged from rural hospitals. F1000 Research 40(150):1-11. https://doi.org/10.12688/f1000 research.6557.1

38. Chalfont G, Mateus C, Varey S, Milligan C (2020) Self-efficacy of older people using technology to self-manage COPD, hypertension, heart failure or dementia at home: An overview of systematic reviews. The Gerontologist 20(20):1-17. https://doi.org/10.1093/ geront/gnaa04

39. Horwitz L (2017) Self-care after hospital discharge: knowledge is not enough. Br Med J Quality Safety 26:7-8. https://doi.org/10. 1136/bmjqs-2015-005187

40. Vorderstrasse A, Lewinski A, Melkus G, Johnson C (2016) Social support for diabetes self-management via eHealth interventions. Curr Diabetes Rep 16(56):1-8. https://doi.org/10.1007/ s11892-016-0756-0

41. Johnson D, Deterding S, Kuhn K, Staneva A, Stoyanov S, Hides L (2016) Gamification for health and wellbeing: a systematic review of the literature. Internet Interventions 6:89-106. https://doi.org/ 10.1016/j.invent.2016.10.002

42. Jonge MJ, Voshaar MAO, Huis AM, van de Laar MA, Hulscher ME, Riel PL (2018) Development of an item bank to measure factual disease and treatment related knowledge of rheumatoid arthritis patients in the treat to target era. Patient Educ Counselling 101(1):67-73. https://doi.org/10.1007/s00281-017-0623-3

43. Tuckson R, Edmunds M, Hodgkins M (2017) Telehealth. N Engl J Med 377(16):1585-1592. https://doi.org/10.1056/NEJMsr1503 323
44. Dwarswaard J, Bakker EJ, van Staa A, Boeije HR (2016) Selfmanagement support from the perspective of patients with a chronic condition: a thematic synthesis of qualitative studies. Health Expect 19(2):194-208. https://doi.org/10.1111/hex.12346

45. Talboom E, Verdijk N, Kasteleyn M, Harmans L, Talboom I, Looijmans-van den Akker I, Geloven N, Numans M, Chavannes $N$ (2017) The effect of integration of self-management web platforms on health status in chronic obstructive pulmonary disease management in primary care (e-Vita Study): interrupted time series design. J Med Internet Res 19(8):e291. https://doi.org/10. 2196/jmir.8262

46. Reidy C, Foster C, Rogers A (2020) A facilitated web-based selfmanagement tool for people with type 1 diabetes using an insulin pump: intervention development using the behavior change wheel and theoretical domains framework. J Med Internet Res 22(5):e13980. https://doi.org/10.2196/13980

47. Voncken V, Amoureus M, de Vries H, Nagykaldi Z, Winkens B, van der Weijden T, Tange H (2017) The impact of participant characteristics on use and satisfaction of a web-based computertailored chronic obstructive pulmonary disease self-management intervention: a process evaluation. JMIR Form Res 1(1):e65851. https://doi.org/10.2196//formative.6585

48. Ammerlaan JW, Mulder OK, de Boer-Nijhof NC, Maat B, Kruize AA, van Laar J, van Os-Medendorp H, Geenen R (2016) Building a tailored, patient-guided, web-based self-management intervention for adults with a Rheumatic disease: Results of a usability study and design for a randomized control trail. J Med Internet R Res Protocols 18(2):e1113. https://doi.org/10.2196/resprot.5735.

49. Neubeck L, Redfern J, Fernandez R, Briffa T, Bauman A, Freedman SB (2009) Telehealth interventions for the secondary prevention of coronary heart disease: a systematic review. Eur J Cardiovasc 16(3):281-289. https://doi.org/10.1097/HJR.0b013e3283 $2 \mathrm{a} 4 \mathrm{e} 7 \mathrm{a}$

50. So C, Chung J (2018) Telehealth for diabetes self-management in primary healthcare: a systematic review and meta-analysis. J Telemed Telecare 24(5):356-364. https://doi.org/10.1177/13576 33X17700552

51. Thurah A, Bremander A, Primdahl J (2020) High-quality RMD rehabilitation and telehealth: Evidence and clinical practice. Best Practice \& Res Clin Rheumatol 34:101513. https://doi.org/10. 1016/j.berh.2020.101513

52. Kilic L, Erden A, Bingham CO, Gossec L, Kalyoncu U (2016) The reporting of patient-reported outcomes in studies of patients with rheumatoid arthritis: a systematic review of 250 articles. J Rheumatol 43(7):1300-1305

53. Snoswell C, Smith A, Scuffham P, Whitty J (2017) Economic evaluation strategies in telehealth: obtaining a more holistic valuation of telehealth interventions. J Telemed Telecare 23(9):792-796

54. Salisbury C, O'Cathain A, Edwards L, Thomas C, Gaunt D, Hollinghurst S, Nicholl J, Large S, Yardley L, Lewis G, Foster A, Garner K, Horspool K, Man M, Rogers A, Pope C, Dixon P, Montgomery A (2016) Effectiveness of an integrated telehealth service for patients with depression: A pragmatic randomised controlled trial of a complex intervention. The Lancet Psychiatry.3(6):1-11. https://doi.org/10.1016/S2215-0366(16)00083-3

Publisher's Note Springer Nature remains neutral with regard to jurisdictional claims in published maps and institutional affiliations. 